\title{
Como se organiza a nova direita no Brasil
}

\author{
CASIMIRO, Flávio Henrique Calheiros. \\ A Nova Direita no Brasil: aparelhos de ação político-ideológica \\ e atualização das estratégias de dominação burguesa (1980 - 2014). \\ Universidade Federal Fluminense, Rio de Janeiro 2016.
}

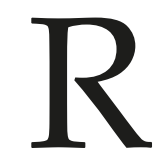

ecentemente acompanhamos um significativo avanço do pensamento conservador em nosso país, também denominado por alguns autores de "pensamento neoconservador". Difundem-se discursos de ódio sobre minorias, exaltando-se o mercado como condição para atingir supostos níveis de liberdade, diminuindo o papel da educação e interferindo na liberdade de cátedra. Perguntamos: quais são as formas de sua produção e circulação?

Em A nova direita no Brasil: aparelhos de ação político-ideológica e a atualização das estratégias de dominação burguesa (1980 2014), de Flávio Henrique Calheiros Casimiro, fortalece-se o esforço de pesquisadores para encontrar as chaves de interpretação dos meandros desse reacionarismo. $\mathrm{O}$ autor chama atenção para a emergência de aparelhos privados de hegemonia (APH) vocacionados à ação política e ideológica de caráter patronal, porta-vozes da classe dominante no Brasil, no período de 1980 a 2014. Seu estudo é pautado no referencial teórico marxista de Antonio Gramsci e na Teoria Sociológica de Pierre Bourdieu. O objetivo do trabalho se deu na articulação das motivações de ordem teórico-política no sentido de compreender a estruturação e organização da burguesia brasileira para a manutenção e atualização de suas estratégias de dominação e acumulação de capital. Com base na análise da relação entre os aparelhos burgueses e a estrutura estatal, o autor discute a indissociabilidade entre Estado e sociedade civil segundo a concepção gramsciana de Estado ampliado. O empresariado, com seus sustentáculos, tem na filantropia um meio de assumir certas funções sociais que seriam de competência do Estado. Trata-se, portanto, de um novo modo de gerenciamento e utilização dos fundos públicos por parte de instituições privadas, vindo em total desfavor de uma política universalizante, igualitária, pública e democrática.

A instituição pública se insere no quadro de estratégias da burguesia como mecanismo de consolidação de referências materiais e simbólicas para introdução de novos elementos na relação capital-trabalho, visando consolidar as mudanças já ocorridas na função do aparelho de Estado e nas políticas sociais. Está em jogo a difusão de uma nova dimensão política de cidadania e de participação. É a classe burguesa se renovando para dirigir "legitimamente" toda a sociedade; neste processo, ocupa-se da disseminação de 
preceitos morais e comportamentais, estruturantes de um outro padrão de negócios e de relação entre indivíduos e classes sociais (a sociabilidade). Além do mais, a burguesia, com suas novas artimanhas, utiliza-se de APHs, organismos sociais coletivos voluntários e relativamente autônomos em face da sociedade política, porém articulados a ela dialeticamente. Por essa via, tem em vista edificar a dominação, formular projetos de poder e difundir a ideologia de mercado. A burguesia e suas frações desenvolvem propostas de políticas públicas pautadas em reformas e privatizações da estrutura estatal e também privatizam as próprias formas de gestão do Estado e suas funções sociais como mecanismo de controle de fundos públicos. Ou seja, criam as próprias regras do jogo que estão jogando.

Determinadas frações das classes dominantes formulam políticas e projetos - lastreadas na atuação de seus intelectuais coletivos -, articulando estratégias de ação no sentido de criar condições para a reconfiguração da estrutura institucional do Estado, tanto como relação interna ao quadro de dominação, como externa, no conjunto das determinações do capitalismo mundializado. É que a reprodução do capital exige atores que, em níveis diferenciados, ajam nos debates políticos e sociais como intelectuais coletivos ou partidos no sentido de interesse de classe.

Criando aparelhos privados de hegemonia, a burguesia brasileira constitui um grupo que, para efetivar e naturalizar o seu projeto de dominação, contempla os interesses das diferentes frações do capital, ainda que de forma distinta e parcial. Semelhante movimento busca agregar desde o proprietário de pequenas fábricas ou empreendimentos comerciais até os grandes conglomerados financeiros e industriais. A formatação da ideologia necessita de "intelectuais coletivos" que compartilhem interesses, organizem a atuação tática, assim como conduzam a formulação de diretrizes de ação enraizadas em um programa político-ideológico. Resta cristalino que a atuação política e ideológica é conscientemente organizada e executada por empresários e intelectuais coletivos que investem capital material e simbólico para defender sua posição dominante. O exercício da dominação de classe pressupõe a existência de um Estado que dê condições e estruture o poder, universalizando os interesses específicos de determinada classe para todo o conjunto social.

Vê-se, pois, que a ação burguesa se organiza de maneira objetiva, estrutural e doutrinária. Casimiro sistematiza em sua tese uma substantiva série de APHs com base em suas formas de atuação, mas destaca que essa separação é meramente de caráter analítico e didático, pois cada um dos aparelhos desenvolve, em certa medida, um pouco de cada uma dessas estratégias ao mesmo tempo. A perspectiva "objetiva” refere-se aos aparelhos da burguesia que agem elaborando diretrizes, alterand o o processo de constituição de políticas públicas, dentre outras maneiras. O estudo evidencia que esse movimento ganhou maior dimensão com as articulações das organizações por ocasião da Assembleia Nacional Constituinte, nos anos de 1980, para a qual financiaram campanhas, lançaram 
candidatos próprios e movimentaram empresários urbanos e rurais. Os aparelhos de sentido "estrutural" são aqueles pautados em um projeto de poder e agem no interior do aparelho estatal. Eles influenciam na configuração da organização estatal, perspectivando a naturalização de valores da ideologia de mercado no Estado e na Sociedade Civil. Do ponto de vista "doutrinário", se baseiam nos aparelhos de difusão da doutrina liberal conservadora, que visa a propagação de suas matrizes liberais, promovendo também o recrutamento de intelectuais orgânicos.

A concepção de "intelectual orgânico", para Casimiro, não se define pelo seu grau de escolaridade ou erudição, mas pelo tipo de ação no âmbito da luta de classes, isto é, pela função que exerce no "trabalho" de construção da base de consenso na sociedade. Tais "intelectuais orgânicos" - segundo o autor, empresários-intelectuais - tiveram um papel fundamental no processo de construção de hegemonia na produção da Constituição Federal de 1988, atuando para a legitimação de um projeto que almejava estabelecer os novos parâmetros de regulação social - estratégia que permaneceu, cresceu e se consolidou contemporaneamente.

Entre as organizações constitutivas da representatividade da burguesia na organização e nas decisões do Estado estão: a Câmara de Estudos e Debates Econômicos e Sociais (Cedes); Grupo de Mobilização Permanente (GMP); Confederação Nacional das Instituições Financeiras (CNF); Associação Brasileira de Defesa da Democracia (ABDD); União Democrática Ruralista (UDR); União Brasileira de Empresários (UB); Movimento Cívico de Recuperação (MCRN); Movimento Democrático Urbano (MDU); Pensamento Nacional das Bases Empresariais (PNBE); Frente Nacional pela Livre Iniciativa (FNLI); Grupo de Institutos, Fundações e Empresas (Gife). Torna-se visível a atuação de APHs, cuja estratégia concentra-se na captura e articulação de uma multiplicidade de Organizações Não Governamentais (ONG) e Fundações Privadas e Associações Sem Fins Lucrativos (Fasfil), dando-lhes a representação de distintas frações e interesses, sentido e organicidade de classe. Dos aparelhos de ação política citados, destacamos o Gife, entidade que se auto declara sem fins lucrativos; reúne representantes de origem empresarial, familiar, independente ou comunitário que investem em projetos com fins públicos. Noos projetos de responsabilidade social propostos pelo Estado, o Gife ganha voz como articulador dos interesses da classe burguesa, pois seu objetivo é fornecer uma aparelhagem preparada para orientar, dirigir e apoiar as intervenções político-sociais do empresariado na sociedade civil.

O Gife, como intelectual coletivo da burguesia, promove a relação entre as distintas posições e interesses intra-classe, registrando sua marca ideológica, identificada com os princípios do neoliberalismo. No campo político, aglutina interesses diversos das Fasfil na perspectiva de um reordenamento do papel do Estado no que se refere ao investimento social privado. Neste contexto, a filantropia, vista como ações positivas executadas por organizações da sociedade civil, torna-se mecanismo da classe burguesa no cumprimento 
das funções sociais do Estado, distribuindo migalhas aos pobres, opondo-se a qualquer política de universalização, ademais de prover formas específicas de controle social.

A perspectiva burguesa é a de aprofundamento do processo de expropriações sociais, fabricando novos "caminhos" de acesso à estrutura estatal e naturalizando novas formas de sociabilidade atreladas às concepções de meritocracia, produtividade, eficiência e competitividade. É a defesa do chamado Estado eficiente, ou Estado necessário, característico da nova roupagem dos pressupostos neoliberais. Como o autor demonstra na pesquisa, a Nova Direita atua de forma institucionalizada no interior do Estado, reconfigurando sua estrutura, dialeticamente, como veículo e resultado do processo de atualização da dominação burguesa em sua expressão capital-imperialista, importante conceito formulado por Virgínia Fontes. Exerce e cobra a coerção, assim como busca "educar" a sociedade para a construção e naturalização da sociabilidade do capital. Critica o Estado, ao mesmo tempo em que está visceralmente intrincada no mesmo como classe dominante. Baseada em uma relação íntima com o Estado (por dentro), a Nova Direita aciona diversificadas estratégias de ação para o aprofundamento das formas de expropriação e rapinagem dos recursos e direitos sociais historicamente constituídos, resultado das contradições e disputas na luta de classes.

É importante destacar a contribuição da tese de Casimiro no sentido de esclarecer com propriedade como atua a Nova Direita, bem como a ideia de que o neoliberalismo não se pauta no pressuposto da ausência do Estado, segundo o qual o mercado deveria funcionar de forma livre - como uma mão-invisível -, mas numa inter-relação com o Estado. Este é acionado de diferentes maneiras, seja na forma de coerção, seja na construção de consenso via educação ou até na diminuição dos direitos - o que presentemente acompanhamos de forma exponencial. A ampliação dos mecanismos de expropriação social é peça chave para pôr em andamento as diversas esferas da vida social, principalmente no interior do Estado.

A elucidação de como tais organizações atuam, tanto no sentido doutrinário - de difusão de diferentes matrizes do pensamento liberal, recrutamento de intelectuais orgânicos e segundo interesses corporativos de suas frações, entretanto unificadas em situação de risco -, quanto na ação considerada mais pragmática de elaboração de diretrizes, intervenção e proposição de políticas públicas, é fundamental para percebermos como a ação estrutural, alicerçada em um projeto de poder, desenvolve estratégias por dentro do Estado. Este, por sua vez, representa uma forma de materialização institucional e veículo fundamental no processo de construção e manutenção da hegemonia do capital.

O fenômeno de mobilização e articulação, dinâmico e contínuo, para a revitalização e permanência da classe burguesa no poder, tão magistralmente analisado por Casimiro, é distinto das formas organizativas tradicionais até aquele momento da Assembleia Nacional Constituinte, nos anos de 1980. Estamos frente a uma estratégia de atualização dos mecanismos de dominação de classe no Brasil, tendo em vista o objetivo de garantia de 
seus interesses de concentração de recursos sociais, de exploração da força de trabalho e de recriação permanente das expropriações sociais. Se o autor oferece um raio X tão contundente da atuação burguesa, a nós cabe pensar que resposta podemos dar do lado de cá dessa trincheira.

Recebido em: 02/04/2020 e Aprovado em 21/05/2020

\title{
Sobre os autores:
}

\begin{abstract}
ANA PAULA DA MOTTA
Professora de Educação Infantil. Mestre em Educação. Doutoranda em Educação pela Universidade do Oeste de Santa Catarina (Unoesc).

\section{MARCO ANDRÉ SERIGHELLI}

Professor de Filosofia. Mestre em Educação. Doutorando em Educação pela Universidade do Oeste de Santa Catarina (Unoesc).
\end{abstract}

